\title{
Significance of Prostate Volume (PV) and Prostate Specific Antigen (PSA) in the Diagnosis of various Prostatic Diseases
}

Dr. Rushabhkumar Somani, Dr. Tejas B Patel*

Assistant Professor, Department of General Surgery, Parul Institute of Medical Science and Research, Parul University, Vadodara, Gujarat, India

DOI: $10.36347 /$ sjams.2021.v09i01.020

| Received: 07.01.2021 | Accepted: 18.01.2021 | Published: 19.01.2021

*Corresponding author: Dr. Tejas B Patel

Abstract

Background: The serum prostate specific antigen for the early detection and screening for prostate cancer are very common used among physicians as the best screening tool for prostate cancer. Objective: The objective is to determine the Significance Of Prostate Volume And Prostate Specific Antigen In The Diagnosis Of various Prostatic Diseases. Methodology: This prospective study was carried out at on 120 patients from July 2018- May 2019. All patients with lower urinary tract symptoms (LUTS), suggestive of prostate enlargement, were included. Patients with urethral strictures, calculi or with a previous history of surgeries and procedures on the prostate were excluded. All patients underwent digital rectal examination, serum PSA measurement and transrectal ultrasonography to measure prostate volume. Prostatic pathology was confirmed by biopsy in all patients after obtaining informed written consent. Results: The mean age was $70.05 \pm 8.35$ years. $52 \%$ of the patients had PSA values between $4-10 \mathrm{ng} / \mathrm{ml}$. There was no statistical correlation between age and PSA. Digital rectal examination had a sensitivity of $65.5 \%$ for detection of prostate cancer. Prostatic volume, as an independent variable, was not significant in predicting malignancy. Total PSA done in all cases was significant for the detection of cancer at levels $>10 \mathrm{ng} / \mathrm{ml}$. Conclusion: Changes in prostate volume (PV) and serum prostate specific antigen (PSA) vary among different ages. Age is found to be significant but showed weak positive correlations with PV and PSA. Only PSA and PV demonstrated a significant and strong positive correlation. The study also demonstrated that serum PSA correlates with age, and this is due to increasing prostate volume with advancing age.

Keywords: Prostate Specific Antigen (PSA), Prostate Volume, Digital rectal Examination (DRE).

Copyright $\left({ }_{0} 2021\right.$ The Author(s): This is an open-access article distributed under the terms of the Creative Commons Attribution 4.0 International License (CC BY-NC 4.0) which permits unrestricted use, distribution, and reproduction in any medium for non-commercial use provided the original author and source are credited.

\section{INTRODUCTION}

The prostate specific antigen (PSA) assay is considered as the most useful marker for detection of prostate cancer $[1,2]$. The prostate cancer is one of the most common malignancies in the world and is the second leading cause of cancer mortality in men. The cancer progress very slowly and asymptomatic at the early stage, patients are unlikely to seek medical help in the early stages. Prostate marker is the only biomarker routinely used in screening and early detection even it has generated considerable debate among physicians as a screening tool. Although PSA is highly specific for prostate, an elevated level is not specific for prostate cancer; some studies have shown increased serum levels of PSA total (tPSA) in benign pathologies [3, 4]. The importance of tPSA and PSA free (fPSA) as tumor marker in evaluation of prostate cancer and also patient at risk is well reported in many studies [5, 6]. Some studies have shown that screening for prostate cancer may have reduced prostate cancer mortality rates, but this remains controversial [7].

PSA is a prostate-specific, but not specific to prostate cancer, and is also increased in other diseases of the prostate (prostatitis, benign prostatic hyperplasia), and in diagnostic procedures, as well as some of the physiological processes. PSA is increased to about $0.4 \mathrm{ng} / \mathrm{mL}$ per gram in benign prostatic hyperplasia $(\mathrm{BPH})$ while this level per gram in cancer rises 10 times, or $4 \mathrm{ng} / \mathrm{mL}$. The increased value of PSA is found in $20 \%$ to $50 \%$ of men with benign prostatic hyperplasia [8, 9]. Approximately $10 \%$ of the male population has a PSA value higher than $10 \mathrm{ng} / \mathrm{mL}$, but don't have cancer.

\section{Material \& Method}

This prospective study was carried out at Parul Sevashram hospital, Vadodara, Gujarat, India on 120 
Rushabhkumar Somani \& Tejas B Patel; Sch J App Med Sci, Jan, 2021; 9(1): 101-104

patients from July 2018- May 2019. All patients with lower urinary tract symptoms (LUTS), suggestive of prostate enlargement, were included. Patients with urethral strictures, calculi or with a previous history of surgeries and procedures on the prostate were excluded. All patients underwent digital rectal examination, serum PSA measurement and transrectal ultrasonography to measure prostate volume. Prostatic pathology was confirmed by biopsy in all patients after obtaining informed written consent.

Serum PSA was estimated on the day of admission before any procedures on the prostate or urethra.

Patients were prepared with proctoclysis enema in the night and early morning, and a transrectal ultrasound was performed on all patients to measure the prostate volume and to calculate the prostate specific antigen density. Prostatic pathology was confirmed by transrectal biopsy in all patients after obtaining informed written consent.

Collected data were tabulated and analyzed for possible association using Chi- square Test, along with sensitivity, specificity and predictive values.

\section{Inclusion Criteria}

All patients were admitted with lower urinary tract symptoms (LUTS) suggestive of prostate pathology between 50-80 yr of age group.

\section{Exclusion Criteria}

1. Patients with other causes of LUTS like urethral strictures or calculi.

2. Previous history of surgeries or procedures on the prostate.

\section{RESULTS}

Study includes Total 120 participants of age group 50-80 year. The mean age in our patient group was $70.05 \pm 8.35 \mathrm{yr} .80 \%$ of the patients were in the age group between 60 to 75 years (Table-1, Fig-1).

Table-1: Age wise distribution of participants

\begin{tabular}{|l|l|l|}
\hline Age group (yr) & Number & Percentage (\%) \\
\hline$<60$ & 10 & 8 \\
\hline $60-75$ & 96 & 80 \\
\hline$>75$ & 14 & 12 \\
\hline
\end{tabular}

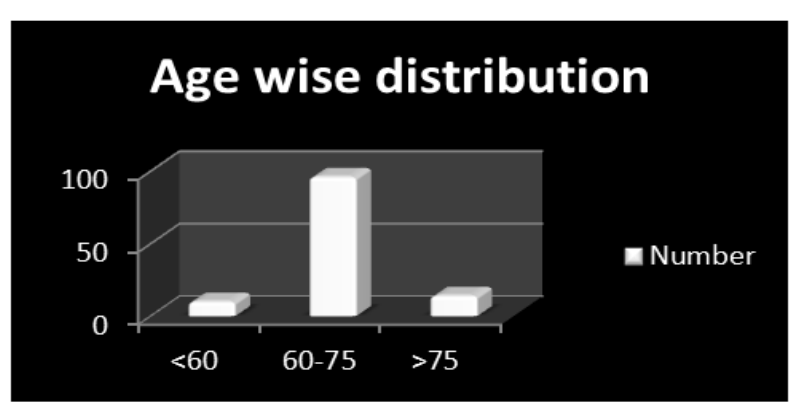

Graph-1: Age wise distribution of participants
Table-2: Showing correlation of S.PSA value with different age group

\begin{tabular}{|l|l|l|l|l|}
\hline \multirow{2}{*}{ Age group(yr) } & \multicolumn{3}{|l|}{ PSA level (ng/ml) } & \multirow{2}{*}{ Total } \\
\cline { 2 - 4 } & $\mathbf{0 - 4}$ & $\mathbf{4 - 1 0}$ & $\mathbf{> 1 0}$ & \\
\hline$<60$ & 06 & 04 & 02 & 12 \\
\hline $60-75$ & 28 & 40 & 22 & 90 \\
\hline$>75$ & 02 & 08 & 08 & 18 \\
\hline Total & 36 & 52 & 32 & 120 \\
\hline
\end{tabular}

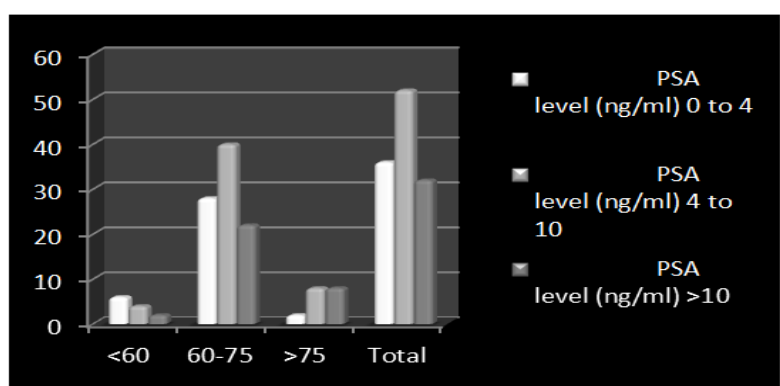

Graph-2: Showing correlation of S.PSA value with different age group

Table-3: Correlation between digital rectal examination and histopathology

\begin{tabular}{|l|l|l|l|l|}
\hline \multirow{4}{*}{ DRE } & \multicolumn{2}{|l|}{ Histopathology } & \multirow{2}{*}{ Total } \\
\cline { 2 - 4 } & & Benign & Malignant & \\
\cline { 2 - 5 } & Benign & 75 & 10 & 85 \\
\cline { 2 - 5 } & Malignant & 10 & 25 & 35 \\
\hline & Total & 85 & 35 & 120 \\
\hline
\end{tabular}

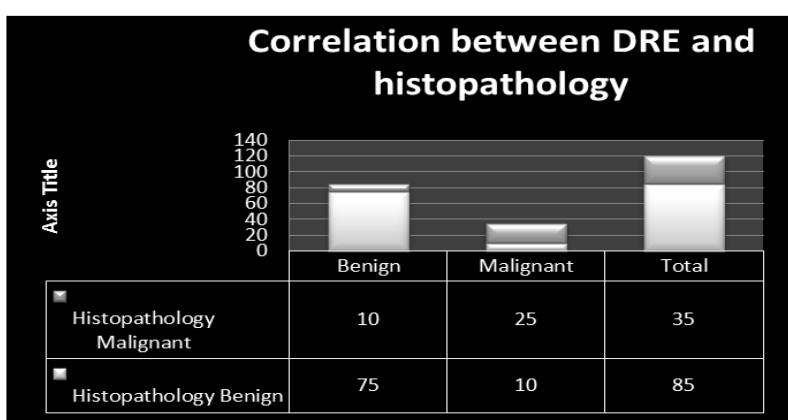

Graph-3: Correlation between digital rectal examination and histopathology

Table-4: Correlation between PSA range and histopathology

\begin{tabular}{|l|l|l|l|l|}
\hline \multirow{4}{*}{$\operatorname{PSA}(\mathbf{n g} / \mathbf{m l})$} & \multicolumn{3}{|c|}{ Histopathology } & Total \\
\cline { 2 - 5 } & & Benign & Malignant & \\
\cline { 2 - 5 } & $0-4$ & 36 & - & 36 \\
\cline { 2 - 5 } & $4-10$ & 50 & 2 & 52 \\
\cline { 2 - 5 } & $>10$ & 5 & 27 & 32 \\
\hline & Total & 91 & 29 & 120 \\
\hline
\end{tabular}

Table-5: Correlation between PSA >10 ng/ml and histopathology

\begin{tabular}{|l|l|l|l|}
\hline \multirow{2}{*}{ PSA (ng/ml) } & \multicolumn{2}{|l|}{ Histopathology } & Total \\
\cline { 2 - 4 } & Benign & Malignant & \\
\hline$<10$ & 78 & 10 & 88 \\
\hline$>10$ & 04 & 28 & 32 \\
\hline Total & 82 & 38 & 120 \\
\hline
\end{tabular}




\section{DISCUSSION}

Prostate-specific antigen (PSA) has been used for prostate cancer detection since 1994. PSA testing has revolutionized our ability to diagnose, treat, and follow-up patients. In the last two decades, PSA screening has led to a substantial increase in the incidence of prostate cancer (PC). This increased detection caused the incidence of advanced-stage disease to decrease at a dramatic rate, and most newly diagnosed PC today are localized tumors with a high probability of cure [10]. PSA screening is associated with a $75 \%$ reduction in the proportion of men who now present with metastatic disease and a $32.5 \%$ reduction in the age-adjusted prostate cancer mortality rate through 2003. Although PSA is not a perfect marker, PSA testing has limited specificity for prostate cancer detection, and its appropriate clinical application remains a topic of debate. Due to its widespread use and increased over-detection, the result has been the occurrence of over-treatment of indolent cancers. Accordingly, several variations as regards PSA measurement have emerged as useful adjuncts for prostate cancer screening. These procedures take into consideration additional factors, such as the proportion of different PSA isoforms (free PSA, complexed PSA, pro-PSA and B PSA), the prostate volume (PSA density), and the rate of change in PSA levels over time (PSA velocity or PSA doubling time).

The advent and refinement of ultrasound technology has provided a new and important method to examine the prostate. Prostatic volume estimation by transrectal ultrasound is a common clinical procedure. It's uses include the pre-treatment assessment of prostate size and interpretation of elevated prostate specific antigen (PSA) levels. Transrectal ultrasound (TRUS) was initially described as a technique to evaluate rectal pathology. In 1963, Takahashi and Ouchi [11-13]. Were the first to describe the use of TRUS to evaluate the prostate. The first clinically applicable images of the prostate obtained with TRUS, were described in 1967 by Watanabe et al., [14].

Prostate growth appears to be related to prostate volume. Numerous studies have confirmed that prostate volume is an important predictor of $\mathrm{BPH}$ progression [15].

In a study by Bohnen et al., 52\% of men with PSA ranging from $1.1-1.5 \mathrm{ng} / \mathrm{ml}$ and in $65 \%$ with PSA ranging from $1.6-2.0 \mathrm{ng} / \mathrm{ml}$, were found to have PV $>30 \mathrm{cc}$. They reported that a serum PSA level >1.5 $\mathrm{ng} / \mathrm{ml}$ could be a functional cut-off value to detect men with PV more than $30 \mathrm{cc} .15$ In a retrospective study, patients with PV $>40 \mathrm{cc}$ who were treated with different alpha-blockers demonstrated increased risk of treatment failure.16 In another study, patients receiving tamsulosin and having smaller total PV responded better on flow parameters. $17 \mathrm{PV}>30-40 \mathrm{cc}$ is an indication for 5-ARI therapy in patients with moderate- to-severe LUTS, which is according to the BPH guidelines of the European Association of Urology. 9 Thus, patients with bothersome LUTS and PV $\leq 40 \mathrm{cc}$ may get benefit using alpha-blocker medication, while 5-ARI therapy (with or without an alpha-blocker) is appropriate for those with $\mathrm{PV} \geq 40 \mathrm{cc}$.

In prostate cancers, a study by Stephen JF [16] concluded that men with smaller prostates had more high-grade cancers and more advanced disease, and suggested that prostate size may be an important prognostic variable that should be evaluated to predict biochemical progression pre- and postoperatively.

1. PSA Density enhances PSA performance. PSA density is calculated as the ratio of Total Serum PSA (ng/ $\mathrm{ml}$ ) to the Prostatic Gland Volume (ml). Isikay et al., [17] a studied the role of prostate-specific antigen density in the early detection of prostate cancer and assessed the hypothesis that PSAD offers significant advantages over prostate-specific antigen (PSA) alone in the evaluation of patients with benign $(\mathrm{BPH})$, pre-malignant (PIN) and malignant prostatic diseases.

Total serum PSA and Prostate volume were the two main indices taken into consideration in our study. A majority of patients were in the age group of 60-75 years in our study, which corresponds to extensive studies done by other researchers $[18,19]$. The relatively higher percentage of patients in the PSA range between $4-10 \mathrm{ng} / \mathrm{ml}$, when compared to larger studies, may be attributed to the other associated features like urinary tract infection and acute retention of urine, as many patients presented to the emergency set up with the above complaints. In the present study, there was no significant rise in serum PSA values with age. This is in contrary to the findings in other larger study populations [20] and may be attributed to the relatively small sample size.

The first clue to a malignant prostate disease is digital rectal examination. In our study, DRE had a sensitivity of $65.5 \%$ in detecting prostate cancer [21]. In a rare study that reported long-term outcome, Gerber et al., [22] and Chodak et al., [23] found that men who had cancer that was discovered on a serial digital rectal examination, seemed to have a more favourable stage shift than men who had cancer that was discovered on initial examination. So, in spite of being a subjective finding in the diagnosis of prostate diseases, it gives the examiner a useful insight to the pathology that he is dealing with.

The PSA density had a high sensitivity (96. $55 \%)$ and specificity (87.3\%) in our study. This is comparable to the larger study done by Van Iersel et al., [24], who had a sensitivity of $92 \%$ for the detection of prostatic malignancy at PSAD values $>0.15$. 


\section{CONCLUSION}

Changes in prostate volume (PV) and serum prostate specific antigen (PSA) vary among different ages. Age is found to be significant but showed weak positive correlations with PV and PSA. Only PSA and PV demonstrated a significant and strong positive correlation. The study also demonstrated that serum PSA correlates with age, and this is due to increasing prostate volume with advancing age.

Acknowledgements: We would like to acknowledge the whole department of surgery of our institute.

\section{Funding: Nil}

\section{Conflict of interest: Nil}

\section{REFRENCES}

1. Peter M. Screening for prostate cancer - the case for. Ann R Coll Surg Eng. 2005; 87:88-9.

2. Wang MC, Valenzuela LA, Murphy GP, Chu TM. Purification of a human prostate specific antigen. Invest Urol. 1979; 17:159-63

3. Kobayashi T, Kawahara T, Nishizawa K, Ogura K, Mitsumori K, Ide Y. Volume- adjusted prostatespecific antigen (PSA) variables in detecting impalpable prostate cancer in men with PSA levels of 2-4 ng/mL: transabdominal measurement makes a significant contribution. BJU international. 2005 Jun 1;95(9):1245-8.

4. Schröder FH, van der Cruijsen-Koeter IN, de Koning HJ, Vis AN, Hoedemaeker RF, Kranse R. Prostate cancer detection at low prostate specific antigen. The Journal of urology. 2000 Mar;163(3):806-12.

5. Brawer MK. Prostate- specific antigen: Current status. CA: a cancer journal for clinicians. 1999 Sep;49(5):264-81.

6. Reigman PH, Vlietstra RJ, Suurmeijer L, Cleutjens CB, Trapman J. Characterisation of the human kallikrein locus. Genomics. 1992; 14:6-11.

7. Lilja H, Ulmert D, Vickers AJ. Prostate-specific antigen and prostate cancer:prediction, detection and monitoring. Nat Rev Cancer. 2008; 8(4):268-78

8. Tefekli A, Karadag MA, Tepeler K, Sari E, Berberoglu Y, Baykal M, Sarilar O, Muslumanoglu AY. Classification of percutaneous nephrolithotomy complications using the modified clavien grading system: looking for a standard. European urology. 2008 Jan 1;53(1):184-90.

9. Moon DG, Yu JW, Lee JG, Kim JJ, Koh SK, Cheon $J$. The influence of prostate volume on the prostatespecific antigen (PSA) level adjusted for the transition zone volume and free-to-total PSA ratio:a prospective study. BJU Int. 2000; 86(6):670-4

10. Dahle SE, Chokkalingam AP, Gao YT, Deng J, Stanczyk FZ, Hsing AW. Body size and serum levels of insulin and leptin in relation to the risk of benign prostatic hyperplasia. J Urol. 2002; 168:599-604.
11. Wannamethee SG, Shaper AG, Morris RW, Whincup $\mathrm{PH}$. Measures of adiposity in the identification of metabolic abnormalities in elderly men. Am J Clin Nutr. 2005; 81:1313-1321.

12. Hammarsten J, Hogstedt B, Holthuis N, Mellstrom D. Components of the metabolic syndrome - risk factors for the development of benign prostatic hyperplasia. Prostate Cancer Prostatic Dis. 1998; 1:157-162

13. Parsons JK, Carter HB, Partin AW, Windham BG, Metter EJ, Ferrucci L. Metabolic factors associated with benign prostatic hyperplasia. J Clin Endocrinol Metab. 2006; 91: 2562-2568.

14. Schuurman AG, Goldbohm RA, Dorant E, van den Brandt PA. Anthropometry in relation to prostate cancer risk in the Netherlands Cohort Study. Am J Epidemiol. 2000; 151: 541-549.

15. Presti JC, Lee U, Brooks JD, Terris MK. Lower body mass index is associated with a higher prostate cancer detection rate and less favorable pathological features in a biopsy population. J Urol. 2004; 171: 2199-2202.

16. Kulkarni GS, Al-Azab R, Lockwood G, Toi A, Evans A, Trachtenberg J. Evidence for a biopsy derived grade artefact among larger prostate glands. J Urol. 2006; 175: 505-509.

17. Fontaine KR, Heo M, Allison DB. Obesity and prostate cancer screening in the USA. Public Health. 2005; 119: 694-698.

18. Fowke JH, Signorello LB, Underwood W, Ukoli FA, Blot WJ. Obesity and prostate cancer screening among African-American and Caucasian men. Prostate. 2006; 66: 1371-1380.

19. 19.Baillargeon J, Pollock BH, Kristal AR, Bradshaw P, Hernandex J, Basler J. The association of body mass index and prostatespecific antigen in a population-based study. Cancer. 2005; 103: 10920 11095.

20. Kristal AR, Chi C, Tangen C, Goodman PJ, Etzioni $\mathrm{R}$, Thompson IM. Associations of demographic and lifestyle characteristics with prostate-specific antigen (PSA) concentration and rate of PSA increase. Cancer. 2005; 106: 320-328.

21. Farnsworth WE. Estrogen in the etiophathogenesis of BPH. Prostate. 1999; 41: 263-274.

22. Fowke JH, Signorello LB, Chang SS, Matthews CE, Buchowski MS, Cookson MS. Effects of obesity and height on PSA and percent free PSA levels among African-American and Caucasian men. Cancer. 2006; 107: 2361-2367.

23. Werny DM, Saraiya S, Blackman D. Prostatespecific antigen levels in diabetics and non-diabetics from the National Health and Nutrition Examination Survey, 2001-2002. Fourth Annual AACR Frontiers in Cancer Prevention Conference.

24. Van Iersel, Fryar C, Carroll MD, Flegal KM. Mean body weight, height, and body mass index, United States 1960-2002. Advance Data from Vital and Health Statistics: National Center for Health Statistics, 2004; 347:1-20. 